\title{
Políticas públicas e a construção da identidade nas relações de trabalho
}

Vanessa A. de Souza* Alexandre Reis Rosa

As transformações no mundo do trabalho a partir da Revolução da tecnologia da informação e do surgimento de novas formas de gestão - representadas por modelos japoneses, italianos e suecos - desenvolvidos como alternativas ao modelo taylorista-fordista, trouxeram consigo uma nova configuração na estrutura ocupacional e nas relações de trabalho (Toni, 2003). A reestruturação produtiva, flexibilização, declínio dos sindicatos, diversificação das relações de trabalho, incorporação maciça das mulheres na força de trabalho e a acirrada concorrência econômica global sinalizam cenários pouco favoráveis aos que ainda vêem o trabalho como elemento central das relações sociais e da construção identitária dos indivíduos. Dentro desta perspectiva, Offe (1989) demonstra a implosão da categoria trabalho na constituição da identidade dos trabalhadores, baseando sua formulação em fatores como: a

Vanessa A. de Souza é Doutoranda em Ciência Política na UFRGS. <cpolvanessadesouza@hotmail.com>. Alexandre Reis Rosa é Administrador pela UFPR. $<$ alexandrereisrosa@hotmail.com>. Este artigo foi apresentado no VII Encontro Regional da UNITRABALHO, na UNISC, em Santa Cruz do Sul - RS em 16 de setembro de 2004. Agradecemos aos comentadores do trabalho pelas sugestões.

\section{Civitas}

v. 5

n. 1 jan.-jun. 2005 p. $197-212$ 
erosão de tradições culturais; a diminuição do tempo dedicado ao trabalho; a expansão do trabalho em serviços; a descontinuidade profissional; e o aumento do desemprego estrutural, que propicia o surgimento de subculturas passivamente hostis aos valores e normas da sociedade do trabalho, involuntariamente inseridos na economia informal. No entanto, apesar dessas transformações por quais passam o mundo do trabalho, consideramos que o trabalho ainda ocupa um lugar de destaque no imaginário coletivo, permanecendo como uma categoria importante no entendimento de uma série de fenômenos sociais, entre os quais a construção de identidades pelo trabalho.

Segundo Caldas e Wood Jr. (1997), o estudo da identidade evolui a partir da relação indivíduo-ego, onde se estabelece a identidade pessoal e num segundo momento, a partir do relacionamento entre a identidade pessoal e a identidade grupal, estabelece-se o grau de identificação do indivíduo com o grupo. No primeiro momento, a identidade constitui uma tentativa de explicação do $e u$, como fruto de uma construção psicológica de si mesmo. Em seguida, a identidade grupal ou social atua como um espelho, que reflete o indivíduo segundo a perspectiva de pertencer àquele grupo, atribuindo-lhe uma auto-percepção que, baseado nas referências atribuídas ao grupo, adquire uma lógica de ação em comum aos demais membros (Machado, 2003). Dessa forma, o grupo passa a representar um meio do indivíduo defender sua existência e visibilidade social, garantindo a priori sua integração à comunidade. Quando um grupo que o representa, não consegue defender sua existência, temos uma "crise de identidade", caracterizando uma identidade social insatisfatória. Como consequência, ocorre uma fragmentação do grupo, levando os indivíduos a buscarem vinculação em outros grupos. Por outro lado, quando há uma identidade social positiva, ou seja, o indivíduo consegue defender sua existência e ter visibilidade social, temos uma afirmação dos indivíduos com o grupo e a construção de uma identidade social forte.

Neste sentido, o objetivo deste artigo é discutir teoricamente a relação entre algumas categorias analíticas que formam nossa base de argumentação: a inclusão social, a cidadania e a identidade nas relações de trabalho. Para refletir a categoria de inclusão, apresentamos as formas de exclusão presentes no mundo do trabalho, e demonstramos em termos teóricos que uma via de inclusão passa pela afirmação de identidade de mulheres, dos negros, daqueles que sofrem discriminação etária e dos portadores de necessidade especiais. Com a afirmação de suas identidades, a partir de organizações oriundas 
da sociedade civil, esses grupos podem defender sua existência e levar ao debate público e a instâncias deliberativas do Estado e outras agências, as demandas que possuem quanto às relações de trabalho. Assim, demonstramos a junção entre atuação cidadã e identidade na luta pela melhoria das condições de vida no mercado de trabalho e novas relações daí resultantes, que implicam em cidadania diferenciada.

\section{O processo de flexibilização e as relações de trabalho}

Ao se refletir a área trabalho a partir da variável cidadania, temos que dirigir a discussão para a construção social da desigualdade. Para tanto, podemos utilizar a noção de "habitus precário" fazendo referência aos setores mais tradicionais da classe trabalhadora alemã, bem como brasileira que são incapazes de atender as demandas pelo contínuo processo de formação e da flexibilidade da chamada sociedade do conhecimento (Souza, 2003, p. 170). De acordo com Jessé de Souza, em sociedades periféricas como a brasileira,

[...] o habitus precário, que implica a existência de redes invisíveis e objetivas que desqualificam os indivíduos e grupos sociais precarizados como subprodutores e subcidadãos, e isso sob a forma de uma evidência social insofismável, tanto para os privilégios como para as próprias vítimas da precariedade, é um fenômeno de massa e justifica a minha tese de que diferencia substancialmente esses dois tipos de sociedades é a produção social de uma "ralé" estrutural nas sociedades periféricas. Essa circunstância não elimina que, nos dois tipos de sociedade exista a luta pela distinção baseada no que se chama de "habitus secundário", que tem a ver com a apropriação seletiva de bens e recursos escassos e constitui contextos cristalizados e tendencialmente permanentes de desigualdade. Mas a consolidação efetiva, em grau significativo, das precondições sociais que permitem a generalização de um "habitus primário" nas sociedades centrais torna a subcidadania, enquanto fenômeno de massa, restrito apenas às sociedades periféricas, marcando sua especificidade como sociedade moderna e chamando a atenção para o conflito de classe específico da periferia (Souza, 2003, p. 177).

Nesse sentido, é que iniciamos uma abordagem das aproximações possíveis entre cidadania e relações de trabalho. Há várias nuanças a serem percorridas, a primeira é o forte discurso da empregabilidade, da formação, da informalidade e da flexibilidade como princípio limitador da construção da cidadania pelo trabalho. Como salienta Ilona Kovács (2002), o trabalho na 
conjuntura atual deixa de ser um direito e se converte numa fonte de rentabilidade para o capital, sendo o trabalhador transformado em custo. Parte importante das ideologias que permeiam o mundo do trabalho são difundidas por atores econômicos internacionais como o Banco Mundial, o Fundo Monetário Internacional (FMI) e a Organização Mundial do Comércio (OMC). A resposta da sociedade a essas questões é atualmente a organização dos interesses do trabalho em nível transnacional por meio de sindicatos e outros movimentos sociais (Kovács, 2002).

Ao se propor atividades alternativas em relação ao trabalho, ele deixa de ser estratégico para parcela significativa da população como mulheres que podem por meio do trabalho manter sua autonomia e independência financeira. Ainda nessa linha, Hirata (1998) chama a atenção para o percurso que os novos modelos produtivos tem tomado, como por exemplo, o aumento do trabalho precário, o declínio dos laços empregatícios, o aumento do desemprego de longo prazo e a presença de empregos instáveis. No Brasil, há um aumento significativo da atividade feminina, que coincide com o aumento da importância da precariedade do emprego, vale dizer, do aumento dos empregos informais.

Ainda nessa linha, segundo Gallino (2002), a normatização que dava ao trabalho um caráter formal está se reduzindo, sendo que o Estado passa a abandonar algumas responsabilidades quanto à regulação do trabalho. Gerando um crescimento do setor informal compreendido como uma área em que as condições de trabalho são pré-modernas ou pré-formais,

Una área donde no existe ningún tipo de legislación estatal, sindicatos (exceptuando algunos proyetos en fase de planificación), no existe contrato acerca del salario o del horario de trabajo; no hay reglamentaciones medioambientales. Una área donde todas las personas están solas en la tarea de procurarse una vida decente o simplemente sobrevivir (Gallino, 2002, p. 10-11).

O trabalho informal não consiste numa fase intermediária para melhorar o caminho para o setor formal, consiste numa questão se sobrevivência. Há estimativas de que metade dos trabalhadores do mundo estejam no setor informal. Na América Latina, no final da década de 1990, de dez postos de trabalho seis eram do setor informal. Gallino (2002) aponta quatro questões que norteiam o crescimento do setor informal nos países em desenvolvimento: (i) o desmantelamento da maioria dos setores públicos da 
economia, frequentemente obrigados a programas de ajuste impostos pelo Fundo Monetário Internacional; (ii) a desregulamentação dos mercados de trabalho no setor formal e o estímulo ao trabalho temporário, cuja fronteira com o trabalho informal é muito tênue; (iii) a cadeia de subcontratação controlada pela Internet; e (iv) as constantes crises financeiras que levam ao desemprego e a pobreza absoluta de milhares de pessoas.

Neste cenário, o posicionamento de Gallino (2002) em relação à Organização Internacional do Trabalho (OIT) é de que esse organismo trabalha com a noção de que as pessoas ficavam no setor informal durante algum tempo e depois ingressavam no mercado de trabalho formal. No entanto, discordamos do autor e indicamos a ausência em sua análise, da categoria analítica difundida pela OIT de "trabalho decente". O primeiro a utilizar o termo, em 1999, foi o diretor geral da OIT, Juan Somavia. Segundo ele, o trabalho decente consiste em diferentes tipos de liberdade e desenvolvimento com base nos direitos dos trabalhadores, na segurança e na oportunidade de emprego. De acordo com Gerry Rodgers (s.d.), o trabalho decente tem como base quatro pontos: (i) inclui o trabalho formal e informal executado em casa, na fábrica, na rua, isto é, uma ampla noção de espaço no mundo do trabalho; (ii) inclui liberdade de associação, organização coletiva e combate à discriminação e ao trabalho forçado; (iii) a insegurança ocorre no trabalho irregular ou temporário por meio de riscos físicos e pela idade, entre outros. Nesse quadro, a OIT defende que é preciso uma legislação que desencoraje a dispensa de trabalhadores e que se criem rotas de volta ao mercado de trabalho; (iv) a OIT defende a criação de um espaço em que as vozes possam ser ouvidas a partir de uma estrutura coletiva que propicie o diálogo social.

Para Rodgers (s.d.), o trabalho decente tem um teto mínimo e não máximo. O mínimo consiste nos direitos universais e nos princípios que refletem os valores e possibilidades de cada sociedade. O importante do trabalho decente é a universalidade dos direitos dos trabalhadores, como a igualdade de gênero a partir de uma base comum de princípios. Nisso se incluem não somente os trabalhadores do setor formal, mas também daqueles segmentos que estão na informalidade. A ausência de uma organização formal e a relativa ineficiência da intervenção do Estado dentro do setor formal e a extensão da economia informal e o trabalho decente, não podem depender de mecanismos de regulação aplicados pelo Estado. É preciso estimular a capacidade e vozes 
de apoio para gerar recursos e incentivos. Isto envolve novas formas de ação e a existência de atores e de novas instituições. Muitos sindicatos têm reconhecido a capacidade dos trabalhadores informais com organizações que são ativas, como tem demonstrado a Índia. Há instrumentos que podem providenciar a segurança do mercado informal com pequenos seguros, talvez sejam mais efetivas do que a política tradicional. Em outras palavras, para a OIT, o trabalho decente pode ser um guia de escolhas políticas para a economia informal.

Ao nosso ver, podemos visualizar algumas dessas formas de organização, em que as demandas dos segmentos que representam capital e trabalho podem se apresentar. Alguns desses organismos, apresentados por Pochmann (1998) e Souza (2004), são: os Conselhos Gestores de Políticas Públicas, como o Conselho Deliberativo de Fundo de Amparo ao Trabalhador que atua nos três níveis de governo, no Conselho Nacional de Seguridade Social junto a Previdência Social, no Conselho de Administração do BNDES, Conselho de Coordenação do Programa Educação para a Competitividade, no Comitê Nacional do Programa Brasileiro de Qualidade e Produtividade, no Conselho Nacional do PRONAF, no Conselho Deliberativo da Câmara Regional do ABC paulista, no Conselho de Administração do Instituto Brasileiro da Qualidade e Produtividade, no Conselho de Implantação do Observatório Permanente de Situações de Emprego e Força Produtiva, no Grupo Interministerial do Programa de Artesanato Brasileiro.

Os autores apontam ainda a extensão do processo de participação como um passo na democratização das decisões no aparelho de Estado e a crescente realização da cidadania. É exatamente a partir desta perspectiva que desenvolveremos a aproximação entre relações de trabalho e cidadania. Para tanto, é preciso apresentar a concepção adotada de cidadania. A trajetória a ser seguida será desenvolvida com base na teoria multiculturalista.

\section{A cidadania e as relações de trabalho}

De acordo com Kymlicka (s. d.), o debate em torno da cidadania aumentou a partir da década de 1990. A estabilidade das modernas democracias depende não somente da justiça, mas também de uma qualidade e atitude dos cidadãos, como exemplo, o senso de identidade nacional, regional ou étnica. 
Para o autor, os direitos políticos e civis tem sido restritos a classe branca proprietária e aos homens, acarretando um déficit de cidadania para as mulheres e aqueles que se encontram na informalidade do mercado de trabalho. ${ }^{1}$ A Nova Direita tem uma visão de cidadania nada comprometida, como exemplo, o desemprego é avaliado como fruto de reestruturação econômica. Suas reformas não têm promovido uma cidadania responsável; no mercado, estendem a desregulamentação e acabam exarcebando as desigualdades de classe em função do desemprego (op. cit., p. 287).

Nesse contexto, uma concepção adequada de cidadania requer o balanço de direitos e responsabilidades. A Nova Direita defende que a forma de se adquirir as virtudes para a cidadania é o mercado e as escolas. No entanto, há outras respostas para essas questões. A esquerda responde ao problema da cidadania passiva, a partir do processo de empowerment ${ }^{2}$ dos cidadãos, com a democratização do Welfare State e a dispersão dos poderes do Estado nas instituições democráticas locais e assembléias regionais (op. cit., p. 289). Já os teóricos da sociedade civil, enfatizam a necessidade de organizações voluntárias na sociedade civil ou associações étnicas, cooperativas, grupos, associações de vizinhança, grupos de mulheres, entre outros.

Diante das posições apresentadas acima, a saída teórica de Kymlicka é definir cidadania não somente como um status que apresenta direitos e responsabilidade, mas também uma identidade e a expressão de uma comunidade política. Há outras formas de exclusão, além das educacionais e econômicas, há grupos de mulheres, negros, portadores de necessidades especiais, pessoas que sofrem de discriminação etária que são excluídos do mercado de trabalho. Nos termos da formulação teórica de Kymlicka, esses grupos foram excluídos não por causa de seu status sócio-econômico, mas por causa da sua identidade sócio-cultural da "diferença" (s. d., p. 302).

Seu argumento é que os direitos comuns de cidadania definidos pelo homem branco, não podem acomodar os grupos minoritários. Para que esses grupos sejam integrados numa "cultura comum" é preciso adotar a concepção de "cidadania diferenciada". Assim, certos grupos só podem ser incorporados

Kymlicka não cita as camadas trabalhadoras, mas dado o enfoque do nosso texto se preocupar com essas camadas eles foram incluídos.

2 Consiste num processo de descentralização do poder, uma espécie de "empoderamento" que proporciona maior autonomia aos grupos. 
numa comunidade política não enquanto indivíduos, mas enquanto grupo. A demanda por "cidadania diferenciada" é uma concepção de cidadania, mas muitas pessoas argumentam que se falar em cidadania de grupos diferenciados é uma contradição com o próprio termo. Do ponto de vista ortodoxo, cidadania é uma definição tratada com indivíduos que têm direitos iguais perante a lei. A idéia de cidadania diferenciada é um desenvolvimento radical da teoria da cidadania, porque como chama atenção Íris Young (apud Kymlicka, 1997), grupos que foram culturalmente excluídos possuem desvantagens nos processos políticos precisando de garantias para a sua representação; bem como grupos excluídos precisam de políticas diferenciadas como os negros e as mulheres. Assim, para que a desigualdade ou desvantagem sistêmica, apresentada pelo mercado cultural, seja compensada aos membros de minorias culturais requer não tratamento idêntico, mas tratamento diferenciado para que as diferenças sejam acomodadas (op. cit., 1997).

Nesse sentido específico do pensamento de Kymlicka, temos a discussão de Michael Walzer (1997) que discute cidadania e o princípio da justiça a partir de um formato pluralístico. Os bens sociais podem ser distribuídos por razões diferentes, com procedimentos diferentes e para diferentes agentes; sendo que todas essas diferenças derivam da diferente compreensão dos bens sociais em si mesmos - é inevitável a produção histórica e cultural de particularismos, o que reforça a discussão até o momento apresentado em termos das identidades.

Walzer ainda discute dois tipos de igualdade: a simples e a complexa. A "igualdade simples" requer a intervenção contínua do Estado para romper constrangimentos causados por monopólios e para reprimir novas formas de dominação. Mas o poder do Estado tem sido objeto de competição das lutas, de grupos de homens e mulheres que têm procurado o Estado para controlar outros bens sociais. Para Walzer (1997) uma das formas de se limitar o poder político é a sua distribuição. Já a "igualdade complexa”, é uma relação entre pessoas, mediadas por bens e dividida entre eles, onde é necessária a diversidade na distribuição dos bens sociais, pois o sistema de distribuição tem se apresentado como um problema em muitas partes do mundo (op. cit., p. 502).

Ao se chegar a esse ponto podemos discutir a própria idéia de cidadania e participação social quanto às relações de trabalho, num espaço como afirma Walzer, em que a sociedade civil é suficientemente democrática para reco- 
nhecer a autoridade e responsabilidade dos participantes, sendo capaz de gerar cidadãos interessados, e o Estado é testado em sua capacidade de sustentar a participação. Para Walzer (s.d.) um projeto de sociedade civil pode ser descrito em três pontos: (i) descentralização do Estado e mais oportunidades e responsabilidade para os cidadãos nas atividades; (ii) a socialização da economia e uma grande diversidade de agentes de mercado; (iii) o pluralismo para realização e sustentação de identidades históricas.

Com essa argumentação queremos demonstrar a importância da construção de identidades no momento de atuação dos cidadãos, nesse caso das relações de trabalho, junto a espaços públicos de decisão, como os vários fóruns anteriormente apresentados. É nesse momento que a manifestação da identidade é fundamental. A partir dessa perspectiva discutiremos a importância da identidade.

\section{A identidade e as relações de trabalho}

Todos os tipos de canais midiáticos trazem constantemente manifestações quanto ao quadro de desemprego no Brasil e em outros países do mundo, demonstrando o quanto o trabalho está ligado a cidadania e a identidade das pessoas. Um relato, dentre os inúmeros que aparecem na imprensa, é bastante elucidativo da relação entre a cidadania, o trabalho, a identidade e os espaços públicos de diálogo. Tirso Leônidas Guimarães Maichacki, residente num quarto de um cortiço no centro de Curitiba no Paraná, acabou no mercado informal vendendo pirulitos. Era um homem de classe média que por ter 53 anos de idade, foi considerado velho para o mercado de trabalho, a partir do momento que não conseguiu encontrar trabalho tornou-se um marginalizado com a situação de desemprego, inclusive perdendo os laços familiares e de amizade. Maichacki relata que o seu "sonho é conseguir um emprego fixo que [lhe] dê a chance de terminar o [seu] curso de Psicologia" (Gazeta do Povo, 22 de fevereiro de 2004).

Nesse caso, podemos entender o espaço do trabalho como um locus que propicia laços entre os sujeitos, capaz de criar identidades (Loguércio, 1998, p. 122). Nessa linha, Kovács (2002) ressalta que a desesperança daqueles que perdem o trabalho, demonstram que o trabalho assalariado é muito mais que mera atividade instrumental, esses trabalhadores perdem sua dignidade e sua 
afirmação pessoal e ficam privados de um conjunto de relações sociais. A partir de um exemplo entre inúmeros, é possível perceber a estreita relação entre cidadania, identidade e trabalho. Para falar em âmbito de uma sociedade altamente complexa e extremamente desigual e excludente como a brasileira é preciso compreender que a democracia exercida pela via partidária, não está conseguindo dar respostas satisfatórias ao quadro de exclusão atual. Por isso discutimos anteriormente a cidadania versus as relações de trabalho.

De acordo com Michael Walzer (2001), a persistente existência de grupos marginalizados revela que o Estado deve desempenhar um papel muito maior do que parecia oportuno há dez anos atrás, o papel do Estado deve estar voltado para a promoção da "igualdade complexa". Uma das formas de reagir a exclusão são medidas antidiscriminatórias, ações afirmativas e discriminação positiva em favor das minorias. Defende Walzer a necessidade de uma "rede de proteção" que permita as pessoas privadas dos "bens sociais", também não sejam despojadas dos meios de subsistência.

Ainda segundo ele, os excluídos foram repartidos em duas categorias. A primeira é daqueles que trabalham em empregos mal remunerados e sobrevive deste modo a margem da sociedade. A segunda categoria é daqueles que não podem trabalhar e se percebem apanhados nas "redes de proteção". Confirmando o exemplo que apresentamos do vendedor de pirulito Maichacki, ao afirmar que quando uma pessoa se encontra na situação de trabalho precário ou desempregado, essa pessoa não é respeitada e possui uma identidade esfacelada, essa pessoa vota, mas é desarticulado e acaba não sendo representada, ficando a mercê dos tele-evangelistas. ${ }^{3}$ Esses excluídos não são fruto de fracassos individuais, mas sim freqüentemente excluídos a partir dos grupos a que pertencem: raça, etnia, sexo e faixa etária no mercado trabalho. Essas pessoas são excluídas pelo sistema e suas fragilidades individuais são fruto dessa própria exclusão, ou seja, a exclusão é de ordem estrutural e não se soluciona com uma transferência pura e simples, a partir de escolas, empregos públicos, influência política ou intervenção da justiça. A existência de grupos excluídos exige, em nome da justiça, que seja realizado um esforço coletivo com o objetivo de fazer a reinserção de seus membros e sua existência independente, em cada esfera de distribuição. Esta é, justamente, a razão

Refere-se a uma analogia aos programas religiosos exibidos em canais abertos de televisão que visam atrair novos adeptos. 
de ser de dois bens sociais relacionados entre si: a proteção social e a educação (Walzer, 2001).

[...] creo que una sociedad en la que no se excluye a nadie es más justa que una sociedad que incluye a los excluidos, valga la expresión; más justa que una sociedad que incluye a las personas marginadas que no participan en un mundo del que dependen, lo quieran o no. La crítica actual hacia los enfoques 'asistenciales' (welfare dependency), cualesquiera que sean sus motivos políticos, se inscribe también en esta perspectiva que sostiene que el objetivo de toda ayuda colectiva y económica, y no en mantener a los individuos en una relación de clientelismo. Esto presupone que toda persona excluida puede alcanzar la participación, que el excluido posee la ambición de participar y el talento necesario para lograrlo y que, con un mínimo de ayuda, podrá desempeñar un papel, al menos en algunas esferas. Estas suposiciones afectan también a nuestra adhesión a la educación pública universal: el niño al que obligamos a asistir a la escuela tiene que poder obtener provecho de esa obligación, es decir, tiene que llegar a ser un ciudadano activo y útil, un trabajador autosuficiente. Todos tenemos que participar en la reproducción de esos ciudadanos y trabajadores. Es una obligación que emana del acuerdo que hemos establecido y que estipula el propósito de mantener una sociedad compuesta por personas que se nos parezcan, una sociedad en cuyo seno sea posible llevar una vida decente y segura (Walzer, 2001, p. 142-143).

Nesse quadro o papel do Estado é importante, mas a sociedade civil de acordo com Walzer ocupa uma posição de destaque para assumir a resolução de muitas dificuldades que devem enfrentar as pessoas excluídas. O papel do Estado deve ser o de gerador de cooperação e ajuda financeira. As associações de igrejas, vizinhos, grupos de interesse e movimentos sociais são instâncias de integração e também fonte de reconhecimento e reabilitação. São instâncias que contribuem na descentralização das esferas de justiça e multiplicam os dispositivos e agentes na distribuição de bens (Walzer, 2001).

Os protestos em geral se dirigem ao Estado, pois cabe a ele a distribuição do poder político. Ao se realizar protestos contra a exclusão, trabalhamos em favor de uma redistribuição e de um novo desdobramento do poder político. $\mathrm{E}$ ao se dirigirem ao Estado os cidadãos e dirigentes contribuem para a reforma do Estado e se convertem em promotores da igualdade complexa. Nesse sentido específico, a melhor forma de tratar a exclusão poderia consistir em aumentar a quantidade de bens disponíveis no lugar de redistribuir os que já existem. Mas a decisão de ampliar ou reformar serviços sociais não pode ser adotado mediante o sufrágio dos trabalhadores e seus beneficiários. 
Essa questão é responsabilidade política incumbida ao conjunto de cidadãos. Os esforços encaminhados a reforçar o mercado e a aumentar o número de empregos são também de natureza política e implicam na necessidade de ter que tomar decisões vinculadas com a infra-estrutura, os incentivos fiscais e o comércio exterior. $\mathrm{O}$ que caracteriza uma comunidade política democrática é o reconhecimento de que todas as transações sociais que mantêm alguns cidadãos a margem e que produzem uma classe de homens e mulheres excluídos, sem formação, sem emprego, sem reconhecimento e sem poder são sempre e em todas as partes, a injustiça da vida na comunidade (op. cit., 2001). No entanto, a sociedade civil é um espaço de cooperação em que os cidadãos aprendem a trabalhar em conjunto a partir de seus interesses comuns. A cidadania, nesse sentido, implicaria uma democratização da própria sociedade civil (2001, p. 166). A partir desses princípios é possível discutirmos o processo de inclusão que o trabalho pode significar em termos de políticas públicas ou da própria ação do Estado.

\section{A inclusão social e as relações de trabalho}

A própria idéia do controle da flexibilidade abre a possibilidade da construção de uma identidade pelo trabalho, que tem tido como base à falta de confiança entre as pessoas que ocupam o mesmo espaço de trabalho, a comunicação entre os trabalhadores abre teoricamente o caminho do diálogo social e da reconstrução de uma identidade, e por conseqüência, uma forma de inclusão social. No Brasil, temos como exemplo, o final dos anos 1970, em que os movimentos sociais construíram uma identidade dentro do espaço do trabalho. Tanto no setor público como privado, produzindo uma nova realidade e com isso produzindo a si mesmos (Berger e Luckmann, 1985).

$\mathrm{Na}$ área trabalho, estas questões localizam-se na possibilidade da criação ou de manutenção de direitos já existentes, a partir de setores mais organizados no espaço da empresa com a presença das comissões de fábrica, com o movimento sindical ou pela construção de novos espaços a partir da associação de moradores, grupos feministas, movimento negro, movimento dos portadores de necessidades especiais e outros.

Nesse mesmo sentido, para que haja representação por parte dos sindicatos é necessário buscar "formas de representação dos trabalhadores temporá- 
rios, mulheres e negros, ação em rede com outros movimentos sociais, no que poderíamos denominar 'sindicalismo-cidadão', inclusive de diferentes países" (Carvalho Neto, 2003, p. 01).

Assim, podemos pensar em segmentos que além das etnias, nacionalidades, e ocupações em tempo parcial, tem grupos como das mulheres que vem sendo excluídos do mercado de trabalho, tornando-se inclusive um reservatório de trabalho pelo número em que estão disponíveis e pelas escalas mais baixas de pagamento (Braverman, 1974). Dentro dessa mesma linha, Nkomo e Cox (1998, p. 341), chamam atenção para pesquisas que revelam que “[...] ser mulher tem efeito negativo nas promoções ou na remuneração também revela que ser homem (grupo majoritário) tem efeito positivo".

No entanto, os autores sugerem como fator de correção para essas distorções, a integração de minorias étnicas, das mulheres e incluímos os portadores de necessidades especiais, pois, segundo eles, a assimilação bem sucedida implicaria perda de identidade e adaptação ao grupo dominante. Assim, entendemos que essa questão apresenta uma problemática teórica muito séria que consiste na afirmação ou não de identidades, que entra num princípio dicotômico de assimilação ou manutenção de uma identidade. É desse quadro que emerge o que Aletta Norval (1994) chama de "lógica identitária", que consiste no processo de construção de uma identidade ou a impossibilidade de dar suporte a um vazio entre a identificação que cria uma totalidade e a identidade negada. A partir da lógica identitária, apresenta-se a possibilidade de desenvolvimento mais democrático que é o reconhecimento de uma lógica peculiar do nunca fechamento da identidade. Ainda que Norval esteja refletindo a realidade específica do apartheid, é possível transpor essa discussão para refletirmos quanto ao mundo do trabalho, pois a essência é a noção de formação de identidades. A questão que se apresenta é que a possibilidade da criação da identidade é o relato de uma exclusão, e em muitos casos o silenciamento do outro. No mundo do trabalho isso pode ser traduzido pelo desemprego ou pela discriminação sofrida na inserção ou no ambiente de trabalho, e essa exclusão consiste na formação de uma identidade. Assim há uma forte relação entre a lógica da inclusão e da exclusão.

É preciso, a partir da emergência de identidades, que os grupos tenham a oportunidade de manter seus traços identitários, se assim for sua escolha. Para Kymlicka (1998), grupos diferenciados para compensar desigualdades 
colocadas aos membros das minorias culturais ou em desvantagem sistêmica, requerem tratamento não idêntico, mas tratamento diferenciado para acomodar as diferenças, e isso envolve o acesso ao mainstream cultural.

A proibição da discriminação amplia as ações por parte do Estado, a partir de leis governamentais de políticas contra a discriminação com base em etnia e gênero e isso tem ampliado a igualdade de oportunidades. A busca pela igualdade de oportunidades não depende somente das ações governamentais, mas também de ações das instituições da sociedade civil.

\section{Considerações finais}

Após estabelecermos as aproximações entre as categorias de inclusão, cidadania, identidade e relações de trabalho, podemos apontar algumas considerações. A proposta inicial de inclusão por meio da afirmação das identidades dos grupos minoritários, reflete a citação de Jessé Souza onde

[...] apenas através da categoria do 'trabalho' é possível se assegurar a identidade, auto-estima e reconhecimento social. Nesse sentido, o desempenho diferencial no trabalho tem que se referir a um indivíduo e só pode ser conquistado por ele próprio. Apenas quando essas precondições estão dadas pode o indivíduo obter sua identidade pessoal e social de forma completa (Souza, 2003, p. 169).

Dessa forma, torna-se importante assegurar o trabalho como um articulador de relações sociais e um forte fator de identidade social. Demonstramos os complicadores presentes quanto ao mundo do trabalho, que reside no crescimento do mercado informal e os problemas enfrentados por identidades específicas como as mulheres, os negros, os portadores de necessidades especiais e aqueles que sofrem de discriminação etária.

Assim, a argumentação segue o caminho de que a inclusão social pelo trabalho passa pela questão central da cidadania, e que um formato dessa inclusão pode ser a movimentação na sociedade civil, com a construção de instituições, comunidades que venham a apresentar suas demandas frente ao espaço público, isto é, que se construam enquanto contra-público para que seus interesses sejam colocados em debate. Há vários espaços que apresentamos no início deste trabalho e cada um deles possui seu canal próprio de comunicação, seja por intermédio de políticas públicas, no caso dos conselhos, seja por meio da capacitação profissional, por parte das associações. O 
objetivo comum reside na ampliação da esfera pública (Fraser, 1996), no sentido de dar voz aos diversos grupos da sociedade civil, que se aproximam do Estado por meio de uma maior participação política.

\section{Referências}

BERGER, Peter L.; LUCKMANN, Thomas. A construção social da realidade: tratado de sociologia do conhecimento. 12a ed. Petrópolis: Vozes, 1985.

BRAVERMAN, Harry. Trabalho e capital monopolista: a degradação do trabalho no século $X X$. Rio de Janeiro: Guanabara, 1974.

CALDAS, Miguel P.; WOOD JR., Thomaz. Identidade organizacional. Revista de Administração de Empresas, v. 37, n. 1, p. 6-17, jan.-mar.

CARVALHO NETO, A. A reforma da estrutura sindical brasileira: pressupostos para uma reforma trabalhista. ABET, digit., 2003.

CIAMPA, Antônio da C. Identidade. In: LANE, Silvia; CODO, Vanderlei (org.). Psicologia social: o homem em movimento. São Paulo: Brasiliense, 1997.

COUTINHO, Maria C. Identidade e dominação nas organizações. Anais do XXIV ENANPAD. Florianópolis: ANPAD, 2000.

FRASER, Nancy. Rethinking the public sphere: a contribution to the critique of actually existing democracy. In: CALHOUN, Craig (ed.). Habermas and the Public Sphere. Cambridge MIT Press, 1996.

GALLINO, Luciano. La informalizacion del trabajo en los países desarrolados: cómo y por qué las condiciones de trabajo en el norte se están aproximando, a la baja, a las del Sur. In: Sociología del Trabajo, Nueva Época, n. 45, primavera, 2002.

Gazeta do Povo, 22 de fevereiro de 2004.

HIRATA, Helena. Reorganização da produção e transformações do trabalho: uma perspectiva Norte/Sul. p. 39-58. In. CARVALHO NETO, Antônio M.; CARVALHO, Ricardo A. A. de (orgs.). Belo Horizonte: IRT/PUC-MG, 1998.

KOVÁCS, Ilona. Como hacer visible el trabajo que el discurso dominante oculta. Sociología del Trabajo; Nueva Época, n. 45, 2002.

KYMLICKA, Will. Ethnic associations and democratic citizenship. In: GUTMANN. New Jersey: Princeton, 1998.

- Justice and minority right. In: GOODIN, R. Contemporary Political Philosophy. Oxfords: Blackwell, 1997.

- Return of the Citizenship: a survey of recent work on citizenship theory. In: BEINER, R. Theorizing citizenship. New York: New York Press, 1997. 
LOGUERCIO, José Eymard. Solução dos conflitos coletivos de trabalho no Brasil: o poder normativo e a arbitragem privada. In: São Paulo em Perspectiva, v. 12. n. 1, 1998.

MACHADO, Hilka V. A identidade e o contexto organizacional: perspectivas de análise. Revista de Administração Contemporânea. Edição Especial, 1997, p. 51-73.

NKOMO, Stella M.; COX JR., Taylor. Diversidade e Identidade nas organizações. In: CALDAS, Miguel; FACHIN, Roberto; FISCHER, Tânia (orgs.). Handbook de Estudos Organizacionais. São Paulo: Atlas, 1998.

NORVAL, Aletta. Social ambiguity and the crisis of apartheid. In: LACLAU, Ernesto (ed.). Making of Political Identites. London: Versos, 1994.

OFFE, Claus. Trabalho: a categoria-chave da sociologia? Revista Brasileira de Ciências Sociais, v. 4, n. 10, junho de 1989, p. 5-20.

POCHMANN, Márcio; BARRETO, Reginaldo Muniz; MENDONÇA, Sérgio Eduardo Arbulu. Ação sindical no Brasil: transformações e perspectivas. In: São Paulo em Perspectiva, 1998, v. 12, n. 1.

RODGERS, Gerry. Decent work, globalization and development. Paper Digit., s.d..

SOUZA, Jessé. A construção social da subcidadania: para uma sociologia política da modernidade periférica. Belo Horizonte: Editora UFMG; Rio de Janeiro: IUPERJ, 2003.

SOUZA, Vanessa A. de. Neocorporativismo e contexto politico no Paraná e no Rio Grande do Sul: um estudo comparativo dos Conselhos Estaduais do Trabalho (19942001). Curitiba: IBERT, 2004 (prelo).

TONI, Míriam de. Visões sobre o trabalho em transformação. Sociologias, Porto Alegre, v. 5, n. 9, p. 246-286, jan.-jun. 2003.

WALZER, Michel. Complex equality. Oxford: Blackwell, 1997.

- Guerra, política y moral. Barcelona: Paidós, 2001.

. The civil society argument. In: BEINER, R. Theorizing Citizenship. New York: New York Press, s.d.

Texto recebido em janeiro de 2005 e aprovado em março de 2005. 